\title{
Research on Application of Central Plains Art Elements in Contemporary Network Animation
}

\author{
Yu Wang \\ Huanghe Science and Technology College \\ Zhengzhou, China
}

\begin{abstract}
Along with invention of film technique at the end of 19th century, people start to master language of animation art; along with continuous development of media technology, different forms of animation art such as film animation and current network animation appear successively; from evolving process of art forms including cave paintings, hand shadow game, shadow play art and raree show, we can feel human's capture efforts for object motion and people's record attempts for motion process. As the main source of artistic creation, Central Plains culture adds more artistic themes to the creation of network animation through a variety of artistic means of art processing. Traditional Central Plains art has rich and colorful species, such as folk color, folk style, local drama, paper-cut art, folklore, etc., the dissemination and inheritance of these artistic characteristics need to be driven by a powerful force in the era of new media. The intervention of digital information technology in the dissemination mode of Central Plains art has changed the mode of artistic creation and artistic appreciation, and thus influenced and changed the thinking mode of network animation art, and ultimately gave birth to the characteristics of network animation art in the era of new media.
\end{abstract}

Keywords-Central Plains art; network animation; inheritance; innovation

\section{INTRODUCTION}

Since the 1980s, the rapid development of digital media technology taking computer technology as a carrier and the ever-changing industrial science and technology has brought great progress to people's lives. With the increasing popularity of the Internet, network technology of multimedia technology has become the mainstream media of digital media. As one of the important forms of the network media of digital media technology, network animation has attached people's favor. Central Plains art has a long history and we can find the original materials from the rich folk art resources during network animation design. The rich resources of Central Plains have provided valuable artistic and cultural resources for animation design, which enable Central Plains art resources to be well applied to animation design, inherit the essence of traditional Central Plains elements, and enhance network animation art to a new height. With the development of new media technology, animation art will exhibit more valuable potential, it can be foreseen that animation art will continue to enhance its vitality with technological advancement. However, after entering the era of new media, animation art with Central Plains art features must make appropriate changes based on the features of new digital media if it wants to get more living space, these socalled changes are not only reflected in the maturity of their own artistry, but also in the generation of more iridescent forms in combination with other media. With the development of new digital media technology and epochal progress, network animation has enriched the artistic expressions of animation, enabled more diverse media and far-ranging application scope, network animation has become one of the most popular forms of animation nowadays.

Research on animation art carrier and dissemination of Central Plains culture has a special significance for the whole study of new media animation art. The continuous emergence of the forces of new era, new technologies and new media let us feel an intense new atmosphere of artistic development of the Central Plains culture. In this era with emerging surprises, the continuous innovation of art allows us to view the powerful vitality of digital media development.

\section{EXPLORATION ON ABUNDANT SPECIES OF CENTRAL PLAINS ART RESOURCES}

Central Plains art resources are an artistic expression form of workers, which is simple and natural, and folk art resources also reflect the unique regional characteristics, which are a miniature of national culture, also an important component of modern art design. Through collation of the species of Central Plains art resources, the paper carries out an in-depth exploration from three aspects-the modeling concept and color style of Central Plains art as well as folklore.

\section{A. Modeling Concept of Central Plains Art}

As an artistic image, Central Plains art is not simply a repetition and true representation of objective things from a simple sense, but rather an outcome of extraction, processing and re-creation using artistic methods with bold imagination of prototype of things from many aspects by folk artists. The molding style of Central Plains art derives from national traditions instead of simple repetition, displacement and variation, it is recreation by extracting elements from traditional art and using modern creation awareness and expression techniques, the created new images have brand new visual images and effect. Its conveying mode contains 
rich constituent elements and visual expression effects, which echo animation art. A comparative study of the molding style of Central Plains art and the modeling concept of animation design can deepen the understanding of the value of traditional arts and help promoting traditional arts. As a newborn field in animation art, network animation embodies integrative development of technology and art. Driven by references of folk art, network animation enriched and expanded its conveying means. In Central Plains folk art, various image characteristics are quite distinct, with simple, generalized, exaggerated and quaint modeling, as well as strong regional characteristics, hence is suitable for animation models. For example, Tangyin paper-cut, Xun County mud toys and other folk arts all pursue the modeling concept of traditional Chinese imagery modeling, and the concise and vivid exaggerated generalization is full of charm and imagination. These numerous Central Plains arts not only reveal the charm of traditional arts incisively and vividly, but also offer abundant creation materials for the creation of network animation art.

\section{B. Color Style of Central Plains Art}

The color expression of Central Plains art is generally simple and bright, coloring by local materials is a major characteristic. The traditional Chinese color concept can be called "five-color view", namely red, yellow, blue, white, black. Black and white are two opposites of color, the opposite of "existence" can be attributed to black, and the opposite of "absence" can be attributed to white, the opposites of existence and absence lay the foundation of ink and wash painting in which black and white take the place of all colors. Meanwhile, the five elements color also form the basic concept of folk art, the five colors symbolize status, character and quality in civilian social fire, drama, mask and ground-opera, Nuo opera masks, there are pithy formulas of "gallant red and wicked white..."[1] Most folk woodblock prints in Central Plains region adopt the five-color overprinting, the intense effect of color juxtaposition is resounding and unequivocal. In addition, folk embroidery and clay sculpture also adopt the five colors. For example: the character colors in Hua County New Year wood-block prints are mainly in black, red, yellow, blue and green, taking bright red and rhubarb as the dominant tones with purple being rarely used, the paintings appear warm colors. By diluting the colors to be translucent with water instead of white powder, and using harmonic color, the paintings appear lower contrast which is bright and elegant. The coloring strokes consist of rendering, flat coating, ink painting and other means, which enhance the expressiveness of painting and echo the taste of Chinese painting, appearing simple, elegant and impressionistic, with a strong Chinese flavor. "Fig. 1"

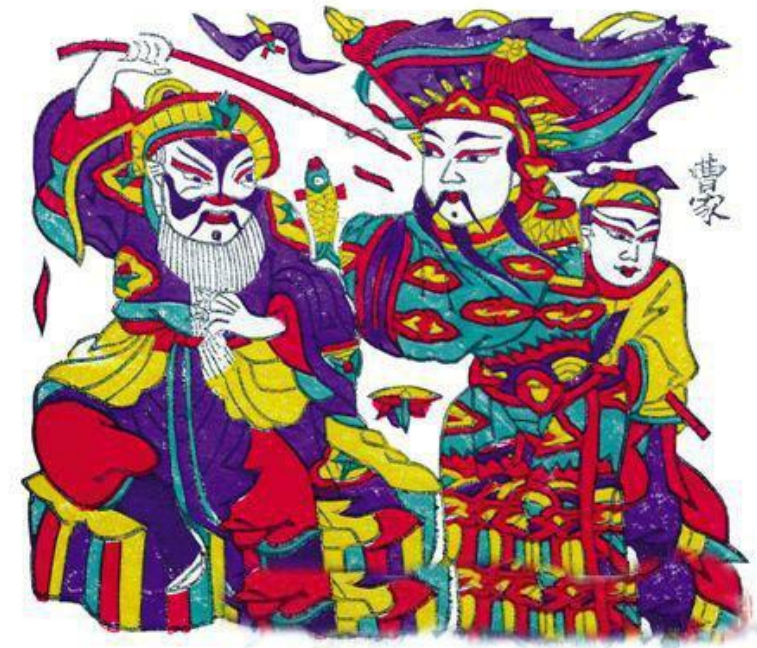

Fig. 1. Hua County New Year wood-block prints

\section{Aesthetics Embodied in Central Plains Art}

Central Plains art is a creation to meet the needs of working people's spiritual life, and an art style applied and circulated among them. It exists in the deep living soil of workers, free from the constraints of utilitarianism and values, and embodies the most basic aesthetic concepts and spiritual quality of human art, with distinctive artistic features and delight of life. Central Plains folk art is a concentrated reflection and embodiment of the local people's aesthetic concepts and values, which is closer to the original ecological folk belief, more focused on the spiritual level, and fully embodies the worship and faith of the Central Plains people, with strong folk cultural characteristics of the Yellow River Basin as well as profound cultural connotations.

\section{RESEARCH ON THE CHARACTERISTICS OF RICH Central Plains Art in NeTwork Animation}

Central Plains art resources are an important part of traditional culture, they have influenced national cultural thoughts and spiritual civilization as the core of cultural heritage and art, and these folk art resources will provide the creation of animation art with valuable materials. By dividing the Central Plains art into multiple fields and conducting more detailed studies on the expression in network animation. Visual performance is the most important part in animation art, hence traditional modeling concept, color style, aesthetic idea of traditional arts are selected from Central Plains art to carry on research.

The application of traditional vision, audition and emotion in Chinese national style animation design is a basic ability for rational screening of portrayal objects in network animation design, also an important means for enhancing the design effects of Chinese national style network animation. Comprehension of many visual emotions are permeated into folk color, hence the paper analyzes the colors and their application in Chinese national style animation from three 
aspects--color theme, scene color and clothing color. The application forms of plastic arts with typical traditional characteristics in network animation are also diverse, the dubbing, background and sound effect in network animation art are also the important parts of auditory art. "Opera is the most representative and widely popular art in traditional Central Plains art, the opera art of Central Plains is flourishing and colorful." [2] The integration of folk drama in network animation will form rich and harmonious forms of artistic expression. As an important element of the whole play, animation script determines the success of the whole animation art. Folklore as the playwriting inspiration of network animation scripts also has a long history, and our inexhaustible cultural resources are an important means for playwriting of network animation and truly touching the emotions of audience. There are many successful cases, such as animation arts created by drawing fragments of Journey to the West are numerous, Monkey King, Princess Iron Fan, Conquers, etc. in 1960s, and annual hottest "dark horse of domestic animation" --- Monkey King: Hero is Back, are all selected from folklore, and deeply impress the emotions of audience.

\section{A. Application of Central Plains Art in Network Animation -Zhuxian Town New Year Wood-Block Prints}

The folk art characteristics of Zhuxian Town New Year wood-block prints provide a wealth of artistic resources for animation creation, its subject matter, content, modeling, color, images, etc. all have their own unique artistic features, and rich art resources that are required by animation development. The unique character modeling techniques, clothing and accessory features, scene structure features of Zhuxian Town New Year wood-block prints all contain deep-seated cultural connotations, by combing with animation art, it can give students new creative ideas and help Chinese animation to get rid of Japanese style and European style. New Year wood-block prints from Zhuxian Town of Kaifeng are the originator of Chinese New Year wood-block prints, also one of the representatives of the Henan Central Plains folk art. The artistic characteristics are manifested by the exquisite use of color, deep and bright colors, color fastness, strong contrast, unadorned ruggedness, satiation and terseness and strong generality. The prints adopt traditional techniques for composition, with distinction in portrait, the clear object, well-arranged scenes and figures show a uniform, solid and symmetrical aesthetic beauty. "The features can be summarized as five points: First, rough lines alternating with crudeness or fineness; second, exaggerated images with small head and big body; third, full composition and bilateral symmetry; fourth, bright colors and strong contrast; fifth, varied bearing of door gods, solemn and dignified." [3] These artistic features enable excellent portability in animation creation works, especially suitable for two-dimensional network animation works of traditional characteristic stories. The most characteristic door god image in Zhuxian Town New Year wood-block prints have become an important reference of ancient generals in students' animation works. Of course, this portability does not borrow some of its external form features, rather it extracts the implicated folk cultural elements, externalizing into symbolic symbols and creating unique animation images. Such as condensing the qualities of Zhuxian Town New Year wood-block prints, retaining the simple and grand character modeling features that not follow rules nor seek proportion, learning from image elements of their bright colors, pure and mighty broad strokes, etc., and applying them to the network animation design as symbols of Central Plains Folk culture "Fig. 2"

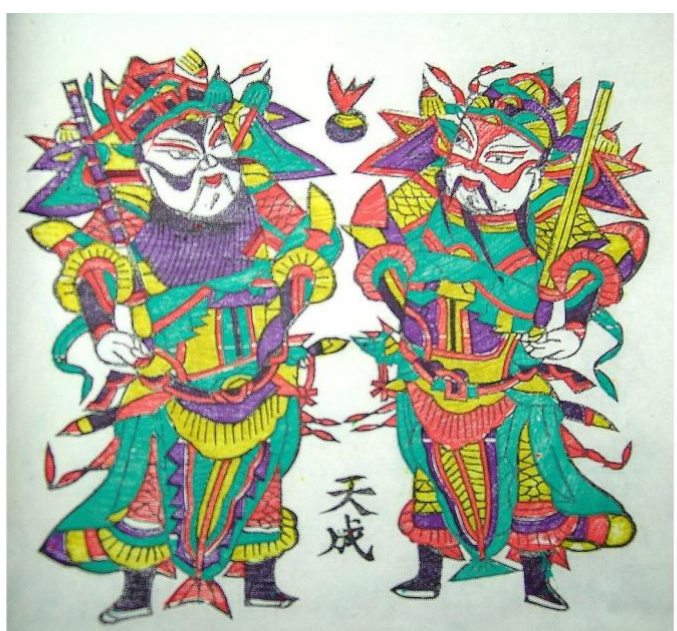

Fig. 2. Zhuxian Town New Year wood-block prints

\section{B. Application of Central Plains Art in Network Animation- Yellow River Chengni inkstone}

Firing carving process of Yellow River Chengni inkstone is ethereal and refined, the color is plain and distant, combined with modeling technology of modern animation art. Therefore, Yellow River Chengni inkstone is not applicable to plane animation, but also suitable for modeling reference of three-dimensional animation. "Yellow River Chengni inkstone is one of four major famous inkstones in China, made of special clay through processing and firing. Yellow River Chengni inkstone can show various colors due to different firing process and time, some Chengni inkstones include multiple colors. Chengni inkstone especially stress carving technology, such as anaglyph, half-rise base, threedimensional and passing inkstone, etc. Carving forms include number, vase, two turtles sitting on wave, sea mammal roaring to the moon, eight beasts fight in water, antique looking stone canal and pavilion tile and other threedimensional inkstones." [4] Plane carving includes landscape and figures, grass, trees and flowers, beasts and bird, rhinoceros watching the moon, mountain and white tower and the Goddess Chang's fly to the moon, etc. With concise carving, fine craftsmanship, scenery and status copying, resemble image, flexibility and liveliness, amusing affection, these carving inkstones are not only one four practical treasures of study, but also art treasure for enjoyment. National cartoon images in our country mainly stay in plane image level and are not enlarged to three-dimensional space. Although it is more challenging to distinguish famous inkstones around China when inkstone image is introduced to animation, just due to similarity of details, animation works successfully strengthening identification degree of 
Yellow River Chengni art characteristics is also a very good supplement for characteristics and popularity of Chengni inkstone. This is an excellent proof for combination and mutual benefit between local folk art and animation. "Fig. 3"

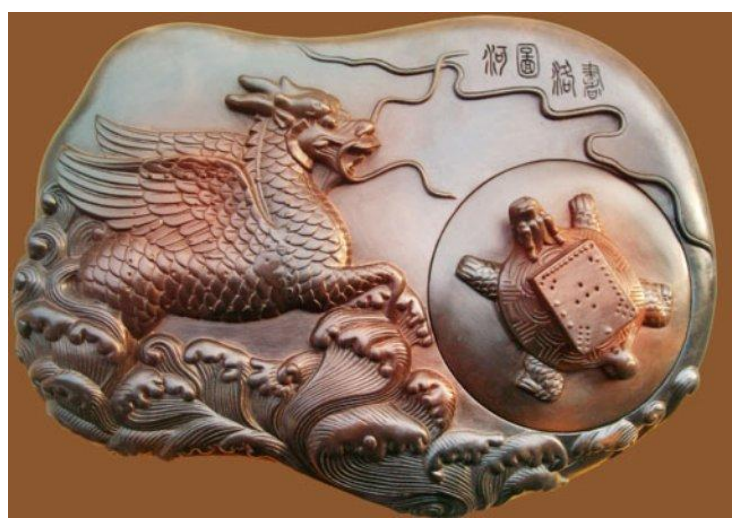

Fig. 3. Yellow River Chengni inkstone

\section{Application of Central Plains Art in Network Animation- Kaifeng Embroidery}

Act characteristics of Kaifeng embroidery are rigorous and clear. Kaifeng embroidery has superb adaptability due to painting basis of process when introduced to animation works. Kaifeng embroidery is artware with very high popularity in Henan. "Kaifeng embroidery is also called Song Dynasty embroidery; Suzhou embroidery, Sichuan embroidery, Hunan embroidery, Guangdong embroidery and it are called five major embroideries in our country, with a long history." [5] Pattern themes of Kaifeng embroidery are mostly flowers and birds, mountains and waters, especially good at painting ancient famous paintings, and there are dozens of stitching methods; Kaifeng embroidery has been developed to double-faced embroidery with varied colors and double-faced with different patterns, stitches and colors. The product is simple and nature, magnificent and lively, colorful but uncommon; the needlework is fine, without revealing side seam; the form is lifelike, and animation works can be quoted wholly or partly. The product cannot only serve as object reflect custom in scene, but also deeply dig Kaifeng embroidery characteristics to make role image. Other art works cannot compare to the unique texture effect. No matter how to use, plain style of Henan folk can stand out to make animation works vivid and nature and possess strong times characteristics and folk interests. "Fig. 4"

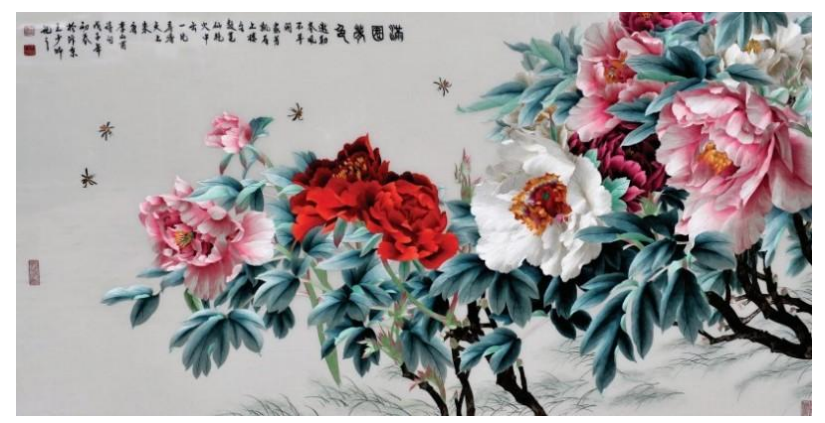

Fig. 4. Kaifeng embroidery

\section{EXPLORATION SIGNIFICANCE IN PROMOTING CENTRAL Plains ART INHERITANCE AND NETWORK ANIMATION DEVELOPMENT}

"Animation education rapidly develops along with growing animation industry, the current animation education obviously does not keep pace with development of animation industry; hysteretic expression of animation education on positioning of animation education is not accurate enough, and ideas of education enter into mistaken position." [6] Separation of animation education and animation industry is not beneficial to long-term development of both. Talent training mode of production-learning-research is one means to realize win-win of animation education and animation industry in colleges and universities, and is an effective way to solve disharmony between rapid development of animation industry and animation education in colleges and universities.

\section{CONCLUSION}

We should research relationship between Central Plains art resources and animation art application, utilize organic combination of animation art, carry forward regional cultural characteristics of Central Plains culture, reflect artistic value and make contribution to animation art development and folk art resources inheritance with Chinese characteristics. In the aspect of animation industry development, Central Plans region has advantages of developed animation industry, rich creation material resources, late-starting advantage and leading animation policy, however, talent, industrial chain, financial capital, enterprise scale are very weak; meanwhile, facing technological development, cultural return, regional development, emerging industry and other development opportunities, we also should respond to the threat of intellectual property protection, imperfect domestic market, competition at home and abroad. Therefore, animation art in Central Plains shall take full advantage of developed advantages of Central Plains art characteristics and determine most effective power point; we should establish perfect animation industry chain, take the road of industrial amalgamation; make the most of late-starting advantage, actively lead the enterprise to strengthen foreign cooperation and communication; utilize current education resources, enlarge cultivation degree of applicable animation talents and high-end animation talents and promote central plains animation to develop well and rapidly. Animation creative industry is honored as sunrise industry with most development potential in 21st creative economy; animation industry development in Central Plains region has an important significance in stimulating economic growth, optimizing the industrial structure, guaranteeing cultural sovereignty and cultural safety, improving regional influence and construct socialist advanced culture.

\section{REFERENCES}

[1] GUO Aihong. Application of North Henan folk art in colleges and universities animation art education[J]. Art and Literature for the Masses. 2011(6):251 
[2] Wang Huawei. The Development Countermeasures on Henan Opera Animation[J]. Art Space, 2010 (15) : 55-56

[3] GAO Fei. Application of Local Folk Art in Henan Animation Education[J]. Beauty \& Times, 2012 (2) : 59-60

[4] GAO Fei. Application of Local Folk Art in Henan Animation Education[J]. Beauty \& Times, 2012 (2) : 59-60

[5] GAO Fei. Application of Local Folk Art in Henan Animation Education[J]. Beauty \& Times, 2012 (2) : 59-60

[6] HAN Wenli. Enlightenment of Henan Animation Industry Talent Situation on animation education in colleges and universities [J]. Journal of Nanyang Institute of Technology 